\title{
ЮРИСПРУДЕНЦИЯ
}

DOI: 10.17805/ggz.2018.1.8

\section{Особенности прав и обязанностей сторон по договору об ипотеке}

\author{
А. Г. Григорьева
}

Московский гуманитарный университет

Автор статьи отмечает, что установленные особенности в отношении прав и обязанностей залогодателя и залогодержателя по договору об ипотеке позволяют сохранять обеспечительную функцию ипотеки на протяжении всего срока его действия.

Ключевые слова: залогодатель; залогодержатель; права; обязанности; договор об ипотеке; недвижимое имущество; ипотека

\section{Features of Rights and Obligations under Mortgage Agreement}

\author{
A. G. Grigorieva
}

Moscow University for the Humanities

The author of the article notes that the determined characteristics regarding rights and obligations of mortgagor and mortgagee under mortgage agreement allow to retain the collateral function of mortgage during the whole period of its validity.

Keywords: mortgagor; mortgagee; rights; obligations; mortgage agreement; real estate; mortgage

Учитывая особенности ипотеки, законодатель устанавливает специальные правила в отношении прав и обязанностей залогодателя и залогодержателя по договору об ипотеке.

Поскольку при ипотеке предмет залога не передается залогодержателю, залогодатель имеет право пользоваться заложенным недвижимым имуществом в соответствии с его назначением. В отличие от общих положений о залоге, содержащихся в ст. 338 Гражданского кодекса РФ (Гражданский кодекс РФ .. , 1994), данное правило является императивным. Согласно ст. 29 Федерального закона «Об ипотеке (залоге недвижимости)» от 16 июля 1998 года (Федеральный закон ..., 1998; далее - Закон об ипотеке), условие договора об ипотеке, ограничивающее данное право залогодателя, ничтожно.

Пользуясь имуществом, залогодатель не должен допускать его ухудшения, а также уменьшать его стоимость сверх нормального износа. 
В соответствии со ст. 37 Закона об ипотеке залогодатель имеет право с согласия залогодержателя отчуждать предмет ипотеки. При этом в договоре можно предусмотреть, что такое согласие не требуется. Особое правило содержится в отношении права залогодателя завещать заложенное имущество, в соответствии с которым условие договора, ограничивающее это право залогодателя, ничтожно. При нарушении залогодателем правил об отчуждении предмета ипотеки законодатель наделяет залогодержателя правом либо обратиться в суд с требованием признания сделки об отчуждении предмета ипотеки недействительной и применения последствий недействительности сделки, либо потребовать досрочного исполнения обеспеченного ипотекой обязательства и обратить взыскание на заложенное имущество независимо от того, кому оно принадлежит. Причем, если приобретатель заложенного имущества в момент его приобретения знал или должен был знать о том, что имущество отчуждается без согласия залогодержателя, приобретатель имущества будет нести ответственность за неисполнение обязательства, обеспеченного ипотекой, солидарно с должником в пределах стоимости такого имущества. Если же в данной ситуации залогодатель не является должником по обязательству, обеспеченному ипотекой, солидарную с должником ответственность будут нести не только приобретатель имущества, но и залогодатель (ст. 39 Закона об ипотеке).

Залогодатель вправе передавать предмет ипотеки в пользование третьим лицам. Если имущество предоставляется в пользование на срок, не превышающий срока обязательства, обеспеченного ипотекой, и будет использоваться в соответствии с его назначением, согласие залогодержателя не требуется. Вместе с тем законом или договором может быть определено, что даже при наличии указанных условий для передачи предмета ипотеки в пользование необходимо получать согласие залогодержателя. В остальных случаях предоставление предмета ипотеки в пользование третьим лицам возможно только с согласия залогодержателя. Если права залогодержателя удостоверяются закладной, передача в пользование третьим лицам предмета ипотеки на указанных условиях возможна, если такое право залогодателя предусмотрено в закладной. Очевидно, что, когда предмет ипотеки передается в пользование третьим лицам без согласия залогодержателя и на него обращается взыскание, затрагиваются интересы залогодержателя. В связи с этим законодатель в ст. 40 Закона об ипотеке предусматривает, что в данной ситуации в случае обращения взыскания на предмет ипотеки право пользование таким имуществом прекращается. При этом законодатель уточняет момент прекращения данного права. Так, если обращение взыскания на предмет ипотеки осуществлялось в судебном порядке, оно прекращается с момента вступления в законную силу решения суда об обращении взыскания на имущество. Если 
же обращение взыскания на предмет ипотеки осуществлялось во внесудебном порядке, то при продаже заложенного имущества с торгов оно прекращается с момента заключения лицом, выигравшим торги, договора куплипродажи с организатором торгов, а в случае приобретения его залогодержателем в собственность - с момента государственной регистрации права собственности залогодержателя на предмет ипотеки.

Еще одно право, которым наделяется залогодатель при ипотеке, заключается в возможности передать заложенное имущество в залог в обеспечение исполнения других обязательств. В этом случае имеет место последующая ипотека. Не допускается последующая ипотека, если она запрещена предшествующими договорами об ипотеке, действие которых не прекратилось к моменту заключения последующего договора об ипотеке. Также законодатель не допускает заключение последующего договора об ипотеке, который предусматривает составление и выдачу закладной. Если, несмотря на установленный запрет, был заключен последующий договор об ипотеке, залогодержатель по предшествующему договору об ипотеке имеет право обратиться в суд с требованием о признании его недействительным.

Если в предшествующем договоре об ипотеке содержатся условия, на которых должен быть заключен последующий договор об ипотеке, такой договор должен быть заключен с соблюдением данных условий. В противном случае требования залогодержателя по последующему договору будут удовлетворяться в той степени, в какой их удовлетворение возможно в соответствии с условиями предшествующего договора об ипотеке. Данное правило содержится в ст. 43 Закона об ипотеке.

В отношении удовлетворения требований залогодержателей при последующей ипотеке, так же как и при других видах залога, действует принцип старшинства, который означает, что требования последующих залогодержателей будут удовлетворены из стоимости предмета ипотеки только после того, как удовлетворены требования предшествующих залогодержателей. Применительно к ипотеке очередность залогодержателей устанавливается на основании сведений Единого государственного кадастра недвижимости.

Залогодатель, заключая последующий договор об ипотеке, обязан до заключения с ним договора сообщать каждому последующему залогодержателю обо всех предшествующих ипотеках заложенного имущества. При неисполнении данной обязанности последующий залогодержатель имеет право потребовать возмещения причиненных убытков. Однако воспользоваться таким правом залогодержатель может только, если будет доказано, что он не мог получить сведения о предшествующих ипотеках, обратившись в орган, который осуществляет государственную регистрацию прав. Кроме этого, залогодатель, заключив последующий договор об ипотеке, обязан незамедли- 
тельно об этом уведомить предшествующих залогодержателей и сообщить им по их требованию сведения о последующей ипотеке.

Исходя из того, что при ипотеке заложенное имущество всегда остается во владении и пользовании залогодателя, законодатель возлагает на него обязанности по содержанию и обеспечению сохранности заложенного имущества. В частности, залогодатель обязан поддерживать имущество в исправном состоянии, в том числе осуществлять капитальный и текущий ремонт в сроки, предусмотренные законодательством, а при их отсутствии - в разумные сроки; принимать меры, необходимые для обеспечения сохранности имущества. Если третьими лицами будут предъявляться требования о признании за ними прав на заложенное имущество, залогодатель обязан немедленно уведомить об этом залогодержателя, а при предъявлении ими иска в суде - привлечь его к участию в деле. Более того, в указанных ситуациях в целях защиты своих прав на заложенное имущество залогодатель обязан с учетом сложившихся обстоятельств использовать способы защиты, предусмотренные ст. 12 Гражданского кодекса. В противном случае залогодержатель может использовать их самостоятельно от имени залогодателя без специальной доверенности и предъявить к залогодателю требование о возмещении понесенных в связи с этим необходимых расходов.

В свою очередь залогодержателю предоставляется право проверять по документам и фактически наличие, количество, состояние и условия содержания заложенного недвижимого имущества, в том числе переданного залогодателем во временное владение третьим лицам.

В целях защиты интересов залогодержателя законодатель возлагает на залогодателя обязанность застраховать за свой счет заложенное имущество в полной стоимости от рисков утраты и повреждения, а если полная стоимость превышает размер обеспеченного ипотекой обязательства, - на сумму не ниже суммы этого обязательства. При этом законодатель применительно к ипотеке устанавливает особое последствие в случае неисполнения данной обязанности залогодателем: залогодержатель имеет право застраховать заложенное имущество и потребовать от залогодателя возмещения понесенных им расходов (ст. 31 Закона об ипотеке).

Более того, если ипотекой обеспечивается заемное обязательство, а в качестве заемщика выступает физическое лицо, последний вправе застраховать риск своей ответственности перед кредитором за неисполнение или ненадлежащее исполнение обязательства по возврату основной суммы долга и процентов за пользование кредитом (заемными средствами). При этом страховая сумма не может быть менее чем 10\% от основной суммы долга и не должна превышать 50\% от основной суммы долга. Выгодоприобретателем по договору страхования ответственности заемщика является залогодержатель 
по обязательству, обеспеченному ипотекой. По данному договору страховой случай наступает, если должник не исполнил требование кредитора о досрочном исполнении обязательства, обеспеченного ипотекой, которое было предъявлено в связи с тем, что должник не уплатил или несвоевременно уплатил сумму долга, если денежных средств, вырученных от реализации заложенного имущества, либо стоимость оставленного кредитором за собой заложенного имущества будет недостаточна для удовлетворения требований кредитора по обязательству, обеспеченному ипотекой.

В свою очередь, залогодержатель вправе застраховать финансовый риск возникновения у него убытков, связанных с невозможностью в полном объеме удовлетворить требования, обеспеченные ипотекой, в связи с недостаточной стоимостью заложенного имущества. Страховая сумма по договору страхования финансового риска кредитора не может быть менее чем 10\% от основной суммы долга. Выгодоприобретателем по такому договору является залогодержатель. В договоре страхования финансового риска кредитора под страховым случаем понимается возникновение у залогодержателя убытков, связанных с недостаточностью денежных средств, вырученных от реализации предмета ипотеки, либо с недостаточной стоимостью предмета ипотеки, оставленного залогодержателем за собой, для удовлетворения требований, обеспеченных ипотекой, в случае обращения взыскания на предмет ипотеки в связи с неуплатой или несвоевременной уплатой должником суммы долга. Убытки залогодержателя, связанные с недостаточностью денежных средств, вырученных от реализации заложенного имущества, либо с недостаточной стоимостью оставленного за собой заложенного имущества, уменьшаются на сумму страховой выплаты, причитающейся залогодержателю как выгодоприобретателю по договору страхования ответственности заемщика.

Если залогодатель грубо нарушает правила пользования заложенным имуществом, его содержания или ремонта, не принимает меры к его сохранности, когда это создает угрозу его утраты или повреждения, а также не исполняет обязанность по его страхованию или необоснованно отказывает залогодержателю в проверке заложенного имущества, залогодержатель имеет право потребовать досрочного исполнения обязательства, обеспеченного ипотекой, а в при неисполнении данного требования - обратить взыскание на предмет ипотеки.

Из анализа ст. 47 Закона об ипотеке следует, что залогодержатель вправе передать свои права как по договору об ипотеке, так и по обеспеченному ипотекой обязательству третьим лицам. При этом договором или законом может быть запрещена их передача другому лицу. В частности, если права залогодержателя удостоверяются закладной, уступка по договору об 
ипотеке или по обеспеченному ипотекой обязательству не допускается. При совершении такой сделки, она будет являться ничтожной.

Лицо, которому переданы права по договору об ипотеке, становится на место прежнего залогодержателя по этому договору. При этом законодатель резюмирует, что при уступке прав по договору об ипотеке осуществляется и уступка прав по обеспеченному ипотекой обязательству. К лицу, которому переданы права по основному обязательству, переходят и права, обеспечивающие исполнение этого обязательства. Такое лицо становится на место прежнего залогодержателя по договору об ипотеке. Вместе с тем диспозитивный характер указанной нормы позволяет предусмотреть в договоре, что права, обеспечивающие исполнение основного обязательства, переходить не будут.

Еще одна особенность, связанная с правами и обязанностями сторон при ипотеке, заключается в том, что права залогодержателя по обязательству, обеспеченному ипотекой, и по договору об ипотеке могут быть удостоверены закладной. В соответствии со ст. 13 Закона об ипотеке закладная является именной ценной бумагой, удостоверяющей право ее законного владельца на получение исполнения по денежному обязательству, обеспеченному ипотекой, без представления других доказательств существования этого обязательства, а также право залога на имущество, обремененное ипотекой. В некоторых случаях составление и выдача закладной не допускаются (например, если предметом ипотеки являются предприятие как имущественный комплекс, либо право аренды на него; если ипотекой обеспечивается обязательство, сумма долга по которому на момент заключения договора не определена и которое не содержит условий, позволяющих определить эту сумму в надлежащий момент). Если права залогодержателя удостоверяются закладной, об этом должно быть указано в договоре об ипотеке.

Установленные законодательством особенности в отношении прав и обязанностей залогодателя и залогодержателя при залоге недвижимого имущества, позволяют сохранять обеспечительную функцию ипотеки на протяжении всего срока действия договора об ипотеке, и тем самым максимально защитить интересы залогодержателя, обеспечив ему возможность удовлетворить свои требования по обязательству, обеспеченному ипотекой.

\section{НОРМАТИВНЫЕ АКТЫ}

Гражданский кодекс РФ, часть первая от 30 ноября 1994 года (1994) // Собрание законодательства РФ. № 32. Ст. 3301.

Федеральный закон «Об ипотеке (залоге недвижимости)» от 16 июля 1998 года (1998) // Собрание законодательства РФ. № 29. Ст. 3400. 
Григорьева Анна Геннадьевна - кандидат юридических наук, доцент кафедры гражданского и предпринимательского права АНО ВО «Московский гуманитарный университет». Адрес: 111395, г. Москва, ул. Юности, 5. Тел.: +7 (499) 374-78-60. Эл. адрес: kafedragp@mosgu.ru

Grigorieva Anna Gennadievna, Candidate of Law, Associate Professor, Department of Civil and Business Law, Moscow University for the Humanities. Postal address: 5 Yunosti St., 111395 Moscow, Russian Federation. Tel.: +7 (499) 374-78-60. E-mail: kafedragp@mosgu.ru

Дата поступления: 12.01.2018 2.

Для циитирования:

Григорьева А. Г. Особенности прав и обязанностей сторон по договору об ипотеке [Электронный ресурс] // Горизонты гуманитарного знания. 2018. № 1. C. 123-129. URL: http://journals.mosgu.ru/ggz/article/view/706 (дата обращения: дд.мм.гггг). DOI: 10.17805/ggz.2018.1.8 